Original published in Journal of Structural Biology 160: 115-124 (2007)

\title{
Are S-layers exoskeletons? The basic function of protein surface layers revisited
}

\author{
Harald Engelhardt \\ Max-Planck-Institut für Biochemie, D-82152 Martinsried, Germany \\ MPI für Biochemie, Am Klopferspitz 18, D-82152 Martinsried, Germany \\ Tel. +49 898578 2650, Fax +49 898578 2641, engelhar@biochem.mpg.de
}

\begin{abstract}
Surface protein or glycoprotein layers (Slayers) are common structures of the prokaryotic cell envelope. They are either associated with the peptidoglycan or outer membrane of bacteria, and constitute the only cell wall component of many archaea. Despite their occurrence in most of the phylogenetic branches of microorganisms, the functional significance of S-layers is assumed to be specific for genera or groups of organisms in the same environment rather than common to all prokaryotes. Functional aspects have usually been investigated with isolated S-layer sheets or proteins, which disregards the interactions between S-layers and the underlying cell envelope components. This study discusses the synergistic effects in cell envelope assemblies, the hypothetical role of $S$-layers for cell shape formation, and the existence of a common function in view of new insights.
\end{abstract}

\section{Keywords}

bacterial cell wall, bacterial cell envelope, outer membrane, peptidoglycan, cell shape, osmotic pressure

\section{Introduction}

Protein surface layers (S-layers) were detected in 1952, when Houwink and LePoole (1952) looked at cell wall fragments of the bacterium Spirillum serpens in the electron microscope. Houwink (1956) was also the first to find S-layers in Archaea, i.e. in Halobacterium salinarum (formerly $H$. halobium), but of course could not be aware of the full impact of his discovery at that time. He offered an indirect explanation for the lack of interest from microbiologists in Slayers in the following years (Murray, 1988): neither Escherichia coli nor Bacillus subtilis, the two model organisms in bacteriology, possessed a regularly structured cell wall (Houwink, 1953). While it became obvious in the recent decades of S-layer research that 2-D protein arrays are common components of the prokaryotic cell wall, it proved to be astonishingly difficult to convincingly explain why they are needed. The purpose to find the function of S-layers led to a set of functional aspects being seen as useful or important for selected organisms, but a common function for all microbes was not obvious (Sára and Egelseer, 1996; Beveridge et al., 1997). This situation has been apparently (and resignedly) accepted. Nevertheless, S-layers have been attractive for biophysical studies and structural research, particularly regarding their perspectives for nanotechnological applications (for reviews see, e.g., Mertig et al., 1999; Sleytr et al., 1999, 2001; Debabov, 2004; Sára et al., 2006). The approaches to improve the structural insight comprise cryo-electron microscopy (Lembcke et al., 1993), scanning probe microscopy (Karrasch et al., 1994; Müller et al., 1996), and X-ray crystallography (Evrard et al., 1999). The hope was and still is to gain a new understanding of the functional basis of S-layer proteins at atomic resolution (Stetefeld et al., 2000; Jing et al., 2002). S-layers have been thoroughly investigated as isolated proteins and 2-D crystals but there are limited studies on S-layers in their natural environment. This approach is more complex but it accounts for the functional conditions of S-layers as opposed to purified protein sheets (Engelhardt and Peters, 1998; Sleytr et al., 2001). 
The structural and functional aspects of S-layers have been discussed in a number of comprehensive articles (Sára and Egelseer, 1996; Beveridge et al., 1997; Engelhardt and Peters, 1998; Sára and Sleytr, 2000; Claus et al., 2005; König et al., 2007). This study is an attempt to reconsider assumptions on S-layer functions in the view of new insights and of mutual effects between cell envelope components. The focus is the role of S-layers in cell-envelope assemblies, for the maintenance and determination of cell shape, and common functional aspects.

\section{Investigation and interpretation of S-layer functions}

2.1. Investigating S-layer characteristics in the cell envelope

The majority of functional aspects were derived from structural investigations of purified Slayers, a strategy that is necessary and fruitful but incomplete. Natural S-layer functions also integrate interactions with partners in the cell envelope. The biophysical consequences of synergistic functions between S-layers and the cell membrane in archaea, and the outer membrane or the peptidogylcan in bacteria are still largely unexplored.

\subsubsection{S-layer-peptidoglycan associations}

S-layer-peptidoglycan associations are mainly mediated by specific contacts. The S-layer homology (SLH) domains found in S-layers of Bacillus spp., Clostridium spp. and relatives (Engelhardt and Peters, 1998) either bind directly to the peptidoglycan (Zhao et al., 2006) or to a pyruvylated carbohydrate that is covalently linked to the peptidoglycan (Chauvaux et al., 1999; Ilk et al., 1999; Mesnage et al., 2000; Schäffer and Messner, 2005). The SLH domain is a modular protein component and occurs in other proteins as well. It is involved in the association of extracellular enzymes with Gram-positive bacteria (Bayer et al., 1998) and of outer membranes proteins in Gram-negative bacteria (Lupas et al., 1994; Engelhardt and Peters, 1998). Amino acid residues participating in the binding process were investigated by May et al. (2006). They identified an arginine residue in the conserved sequence motif TRAE that significantly contributes to or even determines binding and appears to interact with the pyruvylated cell wall component. The S-layers of Lactobacillaceae and of other Gram-positive bacteria lack SLH domains but possess alternative binding sites for charged or neutral targets (Smit et al., 2001; Smit and Pouwels, 2002; Schäffer and Messner, 2005; Desvaux et al., 2006). SLH domains act efficiently as oligomers (Engelhardt and Peters, 1998; May et al., 2006) and it appears likely that every S-layer unit cell can bind at least one target molecule. Specific binding not only associates the S-layer with the cell wall but introduces attachment points for the peptidoglycan network in turn. This should have impact on the flexibility, elasticity, and dilation of the peptidoglycan layer, a functional impact of Slayers that still awaits experimental investigation.
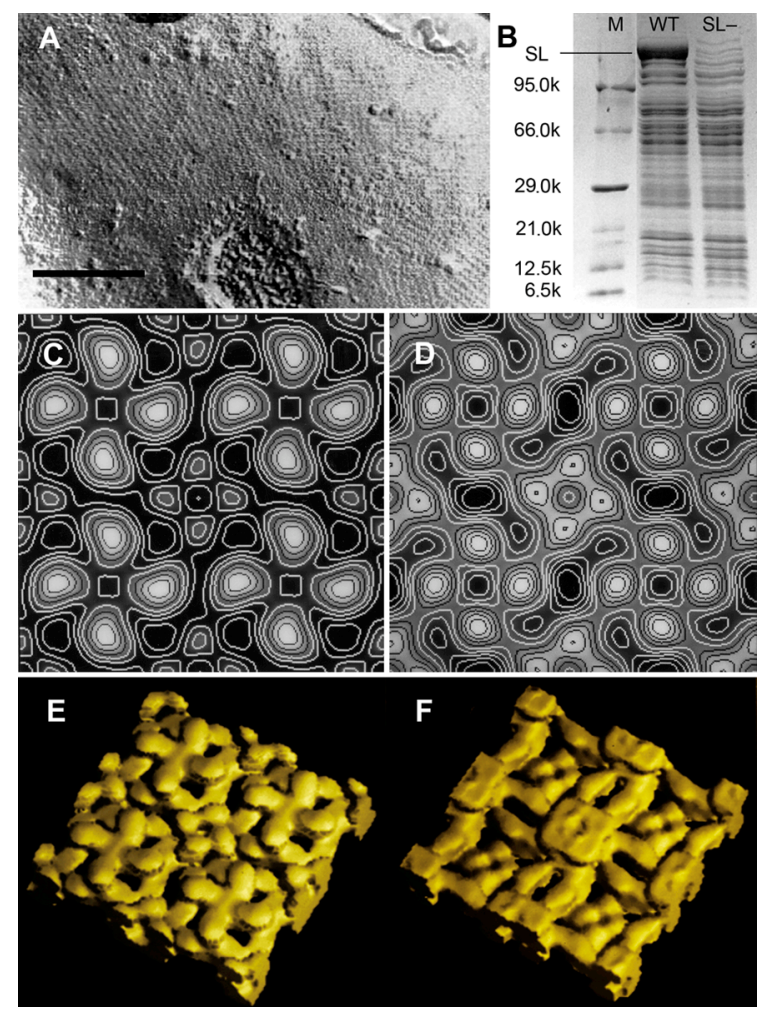

Fig. 1 Conformational changes of the S-layer from Sporosarcina ureae. (A) Freeze-etched and unidirectionally metal-coated (Pt) cell. Bar indicates $200 \mathrm{~nm}$. (B) Polyacrylamide gel electrophoresis of total cell protein from the $S$. ureae wildtype (WT) and an S-layer-negative mutant (SL-). (M) denotes marker proteins and (SL) S-layer protein. (C) Surface-relief reconstruction from averaged unit cells of the electron micrograph depicted in A. The relief height is coded by the grey values; dark areas denote valleys. (D) Surface-relief reconstruction from the outer surface of the isolated S-layer. Note that the central and peripheral tetragonal domains are almost equal in height in contrast to the structure of the S-layer in its natural environment on the cell. (E, F) Surface-rendered model of the isolated S-layer as obtained from negatively stained preparations after 3-D reconstruction following the hybrid approach of correlation averaging and crystallographic reconstruction (Engelhardt et al., 1986), viewed from the outer (E) and the inner (F) surface. Image size $25.6 \mathrm{~nm}(\mathrm{C}, \mathrm{D})$, lattice constant of the Slayer $12.8 \mathrm{~nm}$. 
The topology of S-layers unit cells in the purified and natural form, i.e. bound to the intact cell, may be different. The Sporosarcina ureae S-layer changes its conformation in the isolated state (Engelhardt, 1991), illustrating that the association stabilises a certain 3-D structure of the protein layer in vivo (Fig. 1). Since only a few Slayers have been investigated, it is difficult to assess the frequency of this phenomenon.

\subsubsection{S-layer-outer membrane associations}

Similar observations apply for S-layers in association with the outer membrane of Gramnegative bacteria. The protein lattices of Aeromonas salmonicida and Azotobacter vinelandii relax upon removal from the cells and by cation depletion, and change their lattice constants (Bingle et al., 1987; Dooley et al., 1989; Garduño et al., 1992). As a consequence, the porosity of the S-layers differs in the natural and isolated states.

The association of S-layers to the outer membrane is mediated by interaction via divalent cations with the charged components in the lipopolysaccharide head groups (Garduño et al., 1992; Walker et al., 1994), apparently by specific or semi-specific interactions between the $\mathrm{N}$ terminal region of S-layers and particular forms of lipopolysaccharides (Dworkin et al., 1995; Nomellini et al., 1997; Ford et al., 2007), possibly by carbohydrates of glycosylated S-layer proteins (Engelhardt et al., 1990), by hydrophobic anchors, i.e. covalently bound fatty acids (Peters et al., 1987), or by the S-layer protein itself (Chami et al., 1997; Hansmeier et al., 2004). Similar to the expected situation in Grampositive bacteria, the S-layer has an impact on the physico-chemical characteristics of the underlying cell envelope component. Although experimental data on natural systems are rare (Gerbl-Rieger et al., 1992), measurements with artificial S-layer-membrane (phospholipid) assemblies indicate possible effects (Diederich et al., 1996; Hirn et al., 1999; Küpcü et al., 1998; Mader et al., 1999; Schuster et al., 1998, 1999; Schuster and Sleytr, 2002; Sleytr et al., 2001). Here, S-layers from Gram-positive bacteria were recrystallised on homogeneous lipid monolayers or bilayers. The lipid molecules are immobilised indirectly by non-specific association to the Slayer protein whereby the membranes become less fluid, less flexible, more stable and heatresistant, and presumably more resistant to hydrostatic pressure. The S-layer protein from
Delftia acidovorans (formerly Comamonas acidovorans) tightly binds LPS and can be reconstituted on dimyristoyl phosphatidylcholine (DMPC) membranes via hydrophobic anchoring (Engelhardt et al., 1991; Paul et al., 1992). Fourier-transform infrared spectroscopy revealed an altered phase transition behavior of the lipid membrane (Fig. 2), which is in qualitative accordance with the findings described for other non-specific S-layer-phospholipid assemblies (Diederich et al., 1996; Küpcü et al., 1998). The quantitative effects and functional implications for outer membranes await investigation.

Since the protein content of outer membranes can be very high (Chalcroft et al., 1987; Engelhardt et al., 1990; Kocsis et al., 1993) non-specific but also specific interactions of outer membrane and S-layer proteins are possible or even likely (Engelhardt and Peters, 1998). In contrast to small peptides, which intercalate into the head group regime of lipid membranes but do not influence the phase behavior of the lipids significantly (Weygand et al., 2002), large membrane proteins are in close contact with lipids that form a monomolecular annulus or even larger domains of immobilised lipids around the protein molecules (Jensen and Mouritsen, 2004). If outer membrane proteins were specifically immobilised by the crystalline surface protein, significant effects on the physico-chemical properties of the outer membrane could be expected in addition to possible functional interactions of the membrane and surface proteins.

\subsubsection{S-layer-membrane associations}

Natural association of S-layers with the cytoplasmic membrane occur in Archaea only. Slayers that are anchored by hydrophobic stretches of protein 'stalks' (Baumeister et al., 1989; Baumeister and Lembcke, 1992) presumably act as immobilisation structures for lipids and proteins, with currently unknown consequences for the membrane properties in vivo (Fig. 3). The phase characteristics of membranes containing tetraether lipids is different from that of phospholipid bilayers (Koga and Morii, 2005) but similar effects as discussed in Section 2.1.2 may be expected. Taking the dimensions of the tetrameric coiled-coil structure of the S-layer stalk from Staphylothermus marinus (Stetefeld et al., 2000) as a model, the range of unit cell sizes with lattice constants from 15 to $30 \mathrm{~nm}$, and a projection area of $\approx 0.8 \mathrm{~nm}^{2}$ per lipid molecule (Baba et al., 1999) suggests that up to $5 \%$ of the 

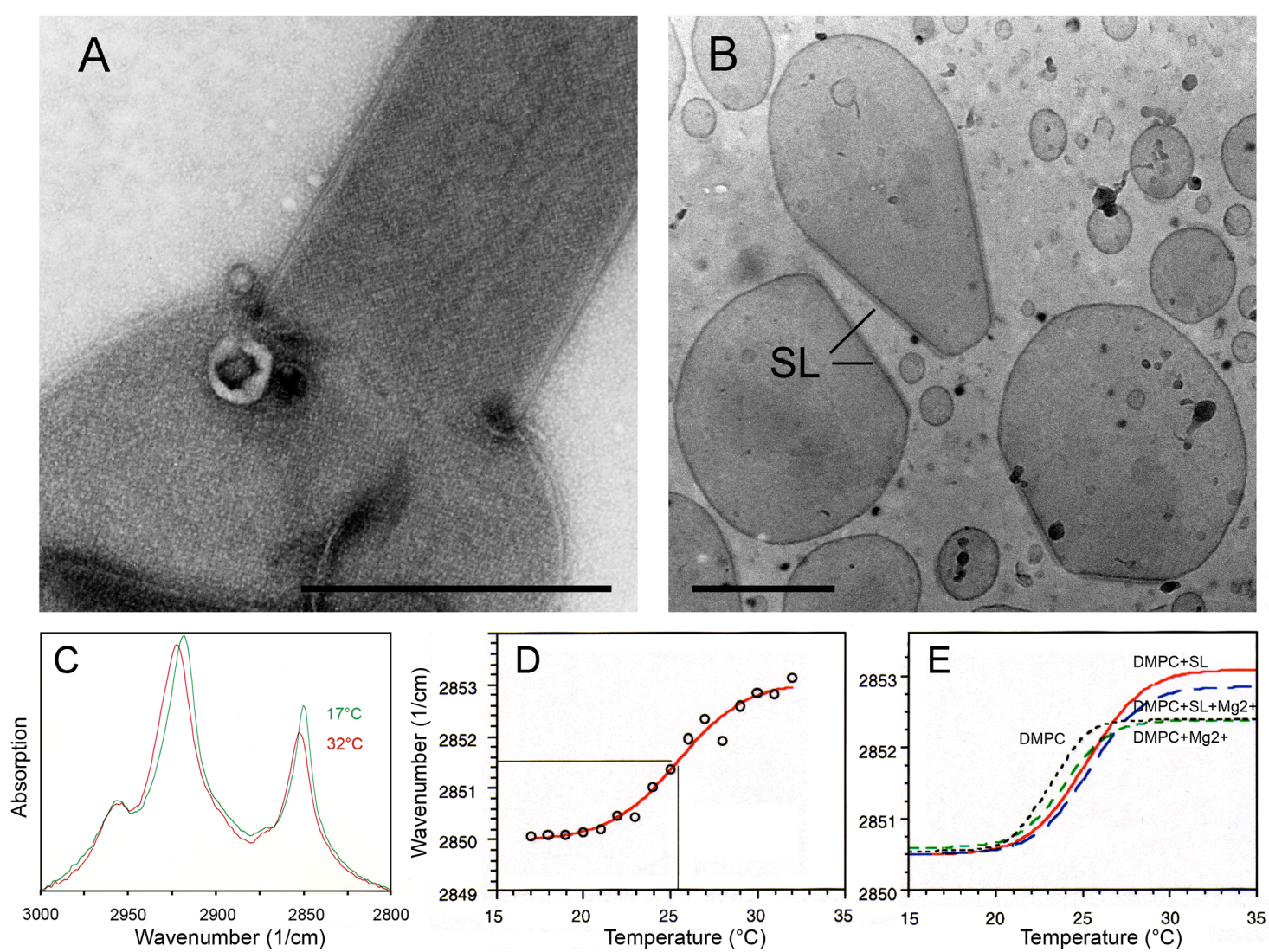

Fig. 2 Reconstituted S-layer protein from Delftia acidovorans on lipid vesicles. (A) Electron micrograph of a negatively stained vesicle partly shaped as a cylinder by a self-contained 2-D crystal of the S-layer. (B) Cryo-electron micrograph of frozen-hydrated vesicles partly covered with S-layer sheets. The lipid membrane made of dimyristoyl-phosphatidylcholine (DMPC) is flattened where the S-layer (SL) formed extended 2-D crystals on the surface. The reassembly products were obtained by the dialysis approach. Images are adapted from Paul et al. (1992). Scale bars indicate $0.5 \mu \mathrm{m}$. (C)-(E) Phase transition behavior of DMPC vesicles and S-layer-lipid assemblies. (C) Fourier-transform infrared spectra from DMPC vesicles covered by the S-layer protein from $D$. acidovorans, indicating the temperature effect on the symmetrical and asymmetrical stretching vibrations of the $-\mathrm{CH}_{2}$ groups of the fatty acids. (D) Positions of the symmetrical stretching vibrations as a function of temperature. The position of the steepest slope defines the phase transition temperature. (E) Phase transition curves from DMPC vesicles (dashed line), from DMPC vesicles in the presence of $\mathrm{Mg}^{2+}$ that bridges the charged carboxyl groups in the DMPC head groups (dashed green curve), from vesicles with reconstituted S-layer protein (red curve), and from DMPC-S-layer assemblies in the presence of $\mathrm{Mg}^{2+}$ (blue curve). The S-layer is anchored by lipopolysaccharides attached to the S-layer protein. The S-layer not only shifts the phase transition temperature of DMPC but also affects the basic order of the fatty acids in the membrane as indicated by the shift to higher wavenumbers. $\mathrm{Mg}^{2+}$ ions only interact with the head groups and do not influence the order of fatty acid residues directly.

lipids may be immobilised by interactions with the S-layer anchor, disregarding other proteins. The important point is that the anchors, unlike common membrane proteins, do not freely float in the lipid phase.

Particularly interesting are stabilising effects of archaeal S-layers, since most of the Archaea and almost all of the Crenarchaeota possess S-layers as the sole cell wall component. It is intuitively clear that the protein layer must be the stabilising agent but experimental data are astonishingly rare (Mescher and Strominger, 1976). One obvious experimental difficulty is the lack of S-layernegative mutants, which indicates the pivotal role of the surface protein. However, reconstituted membranes made of ether lipids and archaeal Slayers could serve as a realistic model for the cell envelope of many species. A theoretical study analyses the osmotic stability of S-layermembrane assemblies, reveals mutual effects, and offers surprising insights into the rationale of S-layer architecture (Engelhardt, 2007). It becomes obvious that the lattice constant and symmetry of S-layers are functionally important. 
2.2. Assumption: S-layers determine and maintain the cell shape

S-layers of archaea that do not possess other cell wall components are expected to maintain or even determine the cell shape (see, e.g., Sára and Egelseer, 1996). There is experimental evidence that the S-layer is shape-maintaining for halobacteria that lose their rod-like form upon removal of the surface glycoprotein or by disintegration of its lattice (Mescher and Strominger, 1976; Engelhardt, 2007), but reports on shape-determining effects are usually based on indirect conclusions.

The most impressive examples for putative shape determination are the S-layers of the thermophiles Thermoproteus tenax and its relatives (Messner et al., 1986a; Wildhaber and Baumeister, 1987), Pyrobaculum (Phipps et al., 1990), and Thermofilum (Stetter, 1986). T. tenax is rod-like up to $80 \mu \mathrm{m}$ in length, and exhibits an apparently constant diameter ranging from 0.3 to $0.5 \mu \mathrm{m}$ for different cells (Stetter, 1986; Zillig et al., 1981). The S-layer is very stable as attempts to dissociate isolated layers failed. The constant diameter of individual rods is consistent with the formation of self-contained 2-D lattices (Wildhaber and Baumeister, 1987). S-layers indeed have an intrinsic potential to assume a stable shape, thereby minimising the energy state, and to form cylinders upon reassembly (Messner et al., 1986b). They are even capable of reshaping lipid vesicles made of DMPC upon forming selfcontained lattices (Fig. 2; Paul et al., 1992).

However, if the formation of self-contained lattices were a principle of shape determination, why then are other archaea not shaped accordingly, especially as 2-D lattices from $p 1$ to $p 6$ symmetries have the capacity to form selfcontained cylinders (Paul et al., 1992)? The cells of Sulfolobales (Brock, 1981; Prüschenk et al., 1987), Desulfurococcales (Wildhaber et al., 1987), Nanoarchaeum (Huber et al., 2002; Briegel, 2005), Archaeoglobus (Kessel et al., 1990) and of other archaea are rounded or irregularly shaped in thin-sectioned preparations. S-layers on a sphere, or on apparent half-spheres at the poles of rod-like cells, possess sites of dislocations (Harris and Scriven, 1970) and/or disclinations to cover the surface (Messner et al., 1986a; Wildhaber and Baumeister, 1987; Pum et al., 1991). S-layer proteins do have the capacity to cover both spheres and rods at the same time, as reflected by artificial reconstitution of S-layers on lipid vesicles (Paul et al., 1992; Mader et al.,
1999). Fig. 2 illustrates the two modes of reassembly. Moreover, Haloferax volcanii and Halobacterium salinarum possess very similar Slayers but distinctly different cell shapes, i.e. flat to irregular and rod-like (Kessel et al., 1988; Pum et al., 1991; Trachtenberg et al., 2000). Pum et al. (1991) examined the role of S-layers with lobed cells and discussed the significance of lattice faults for growth, cell fission and shape. They observed the shape-modifying impact of lattice inclinations and suggested, in contrast to other hypotheses, a shape-determining role for S-layers of spherical, irregular and flattened cells. Taken together, it becomes evident that the inherent properties of S-layers are probably insufficient to constitute a distinct shape-determining function by themselves, beyond that of a passive shapemodifying effect. There is obviously a need for additional structural or functional ingredients.

The intriguing question is how shapedetermination in sensu stricto is defined. Recent results from cytoskeleton research help to address the problem. The peptidoglycan has usually been assumed to determine the shape of bacteria (Beveridge, 2006). Studies with B. subtilis now reveal that cytoskeletal elements of the Mre system and related proteins are responsible for the definition of a typical cell form by determining the manner in which the peptidoglycan grows (Daniel and Errington, 2003; Leaver and Errington, 2005; Stewart, 2005; Carballido-López, 2006). Basically, it is the molecular machinery controlling the mode of peptidoglycan synthesis and influencing cell division that actively determines the shape of the murein sacculus and eventually of the cell, rather than the peptidoglycan itself that passively remains in the form it was given. The situation may even be more complicated with prosthecate bacteria such as Caulobacter crescentus (Briegel et al., 2006). Nevertheless, shape maintenance is of course an indispensible component of the mechanism of shape determination. This insight leads to a useful definition: shape determination is the result of a process, i.e. the mode of cell wall synthesis and its underlying mechanisms, while shape maintenance is an effect of the cell wall properties and depends on the stability of the respective components.

Applying this view to archaeal S-layers, we must question the location and mode of protein translocation and insertion. The fact that crystal growth takes place at crystal edges and sites of crystal faults points to the putative distribution of 
the translocation machinery. Spherical archaea should therefore not exhibit distinct locations for S-layer protein transport during growth. As a consequence, the monomers are potentially available at arbitrary sites on the surface, leading to polycrystalline S-layer patterns that are not prone to reproducibly form self-contained cylindrical assemblies. A random distribution of protein translocators presumably does not enforce sophisticated mechanisms and can thus be regarded as primordial. Those cells are principally determined to be spherical but may be irregularly shape modified by faults in the protein lattice or become flattened by the physico-chemical properties of the S-layer-membrane system (Engelhardt, 2007).

Rod-shaped archaea, on the other hand, can be expected to organise the transport machinery in distinct regions of the cell membrane, creating ring-like growth zones of the S-layer. Now, the surface protein would assemble in a more coordinated manner, preferrably forming a cylindrical layer. The coordinated spatial distribution of membrane proteins, particularly of components of the Sec machinery, has already been observed in bacteria (Campo et a., 2004; Shiomi et al., 2006). The local organisation of protein translocation appears reasonable also from another point of view, particularly regarding the extremely long cells $(80 \mu \mathrm{m})$ of $T$. tenax and relatives. If the S-layer protein transport occurred at any place along the cell cylinder, the molecules would either occupy most of the periplasmic space uselessly, or they could even go astray if they were not anchored to the cell membrane. The hypothesis of local (or dislocated) S-layer assembly and corresponding protein transport could be tested easily by labeling experiments (Howard et al., 1982). Cytoskeletal proteins have already been detected in Archaea, although their functions are still enigmatic (Löwe et al., 2004; Roeben et al., 2007). Cryo-electron tomography may help to identify corresponding cellular structures in native cells (Baumeister, 2005; Kürner et al., 2005).

The conclusion from these considerations is that S-layers may be shape-maintaining and shapemodifying but they are not shape-determining in a strong (process-related) sense.

\subsection{Assumption: S-layers do not have a common function}

None of the various functional aspects of S-layers discussed in the literature to date appear to have

\section{Table I}

Primary and secondary functions of S-layers

Primary functions Secondary functions

Cell stabilisation: Compartmentalisation:

Mechanical stabilisation Periplasmic space

Thermal stabilisation Pore-formation in conjuction

Osmotic stabilisation with outer membrane proteins (hypothetical)

\section{Protection against environmental factors: \\ Protection against particles Protection against immun- ological defense \\ Protection against predators \\ Interaction with environment: Ion trap, metal binding, biomineralisation matrix Protein immobilisation Phage receptor Adhesion to surfaces Specific contacts Pathogenic virulence factor}

the attributes of a general function that would be important for the majority of prokaryotes (Sára and Egelseer, 1996; Beveridge et al., 1997; Sleytr et al., 2001). This arouses the suspicion that the search for a general S-layer function might end unsuccessfully. The conclusion, however, that no common functional principle exists because of missing evidence, would be illegitimate. We have certainly not judged all (known and unknown) functions in the light of all relevant criteria because we are missing a comprehensive overview of the general and specific ecological characteristics of the organisms' natural environments. This is illustrated by the fact that S-layernegative mutants of bacteria are easily obtained in laboratory cultures and in fact outgrow the wildtype (e.g., Baldermann et al., 1998) but we have been unable to satisfactorily explain why Slayers are advantageous in the wild, with only few exceptions (Koval and Hynes, 1991). A general function, if it exists, is shared by the layers of all microorganisms. This assumption essentially considers the original functions of protein layers. However, the significance of those functions might have been modified in the course of evolution, so that they are not evident or dominating in all species today. 
It is likely that protein layers stabilised early cells as primitive precursors prior to the eduction of more complex wall polymers such as peptidoglycan or pseudomurein (Dose and Rauchfuss, 1975; Sleytr and Plohberger, 1980). Since structural integrity is an absolute requirement for cells, the stabilising effect of protein layers can be regarded as more important and essentially basic compared to, e.g., protection against immunological defense that did not play a role until higher organsims came into existence. So, primary, basic, or primordial functions of Slayers can be distinguished from secondary, specific, or acquired ones. The compilation of functions in Tab. I is probably not complete, but it illustrates that the primary functions comprise features that are clearly basic to cell walls in general and originate from an inherent requirement of biological cells. Mechanical and osmotic stabilisation is a general requirement, particularly for microorganisms living in unprotected environments. A theoretical analysis of the contributions of archaeal S-layers to cell integrity and structural maintenance upon osmotic stress is given in Engelhardt (2007). Thermal stability is not a special function of the cell wall but S-layers might contribute to it mechanically. Cells experience a shift in osmotic pressure $\pi$ when they are transferred from cold to boiling water $\left(\pi=\mathrm{RT} \cdot \Sigma \mathrm{c}_{\mathrm{i}}-\right.$ where $\mathrm{c}_{\mathrm{i}}$ denotes the concentration differences of osmotically active substances). Drastic temperature changes may happen near black smokers, for instance. All basic characteristics in Tab. I refer to the compensation of forces that could jeopardise the membrane and the integrity of cells.

The specific functions reflect interactions with and adaptations to the environment. The protection against particles (e.g. macromolecules), is likely to be of importance for cells but S-layer pores are quite variable in size (Engelhardt and Peters, 1998) and do not generally protect underlying cell wall components from the attack of lytic enzymes (Sára et al., 1990). Another effect of limited porosity is the creation of a periplasmic space. The biological significance of this compartment is apparently accepted for Gram-negative bacteria but has probably been underestimated for Gram-positive bacteria and Archaea. Recent investigations by cryosectioning and cryo-electron tomography showed that $B$. subtilis, S. aureus, and mycobacteria, i.e. S-layerless organisms, have evolved a periplasmic space
(Matias and Beveridge, 2005; Matias and Beveridge, 2006; Wang et al., 2000; Hoffmann et al., unpublished results). Nevertheless, the benefits of a periplasm are certainly secondary to the basic mechanical protection of cells.

Archaeal S-layers retain the primordial function in a particularly clear manner where they represent the only cell wall component. Mechanical, osmotic, and possibly thermal stabilisation of cells are indispensible achievements. It is therefore not astonishing that spontaneous S-layer-negative mutants have not been detected in Archaea (Felicitas Pfeiffer and Helmut König, personal communications). Investigations of viable S-layer-less mutant cells were especially helpful since the particular contributions of S-layers to the stability of archaeal cells are still unexplored. Despite this lack, it is apparent that S-layers possess a common function in Archaea by generally providing cell stability.

While this view is essentially not in contradiction to other discussions (Sára and Egelseer, 1996; Beveridge et al., 1997), it is not clear whether it holds true for bacterial S-layers as well. The eduction of other cell wall components such as peptidoglycan has attenuated the significance of mechanical stabilisation by S-layers but there is no obvious reason why they could not still act as structural protectants. Unfortunately, experiments addressing this question do not exist to the best of my knowlege, but indirect evidence supports a corresponding role of S-layers in Bacillus spp. at least. Beveridge et al. (1997) described the characteristics of the Gram stain and discussed the increased integrity of stained cells possessing an S-layer. Moreover, species that are devoid of an S-layer seem to have developed a particularly thick peptidoglycan. Recent investigations revealed a thickness of the peptidoglycan-teichoic acid network of $\approx 33 \mathrm{~nm}$ for $B$. subtilis (Matias and Beveridge, 2005) and $19 \mathrm{~nm}$ for $S$. aureus (Matias and Beveridge, 2006). The peptidoglycan of bacilli and clostridia possessing an S-layer is considerably thinner and measures only 3-6 nm (Beveridge and Graham, 1991). Interestingly, Bacillus anthracis and Brevibacillus brevis (formerly Bacillus brevis) even bear double Slayers (Couture-Tosi et al., 2002; Tsuboi et al., 1989), a strategy that is also observed with Aquaspirillaceae (Austin et al., 1989; Smith and Murray, 1990) and some archaea (Phipps et al., 1991; Firtel et al., 1994). 


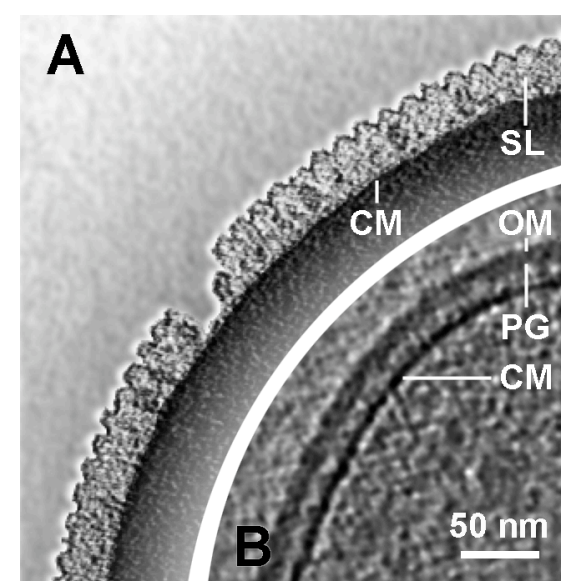

Fig. 3 Cell envelopes of an archaeon and a Gram-negative bacterium in a near-to-life state as obtained by cryo-electron tomography. (A) Section through the tomogram of an iceembedded cell of Pyrodictium abyssi. The S-layer (SL) is anchored via long stalks in the cell membrane (CM) and defines the quasi-periplasmic space of the cell wall. The cytoplasmic density is removed. (B) A corresponding tomographic section through an ice-embedded cell of Escherichia coli, showing the cell envelope with the cell membrane (CM), the peptidoglycan (PG) and the outer membrane $(\mathrm{OM})$. Note the considerable distance between the cell membrane and the peptidoglycan. The images were kindly provided by Stephan Nickell and Christian Hoffmann, Martinsried.

Gram-negative bacteria are usually characterised by a thin peptidoglycan layer (Beveridge and Graham, 1991) that compensates for the osmotic pressure since the cytoplasmic membrane is not expected to withstand higher pressure differences. The non-invasive and structure-preserving techniques of cellular cryo-electron tomography (Baumeister, 2005; Lucic et al., 2005) and cryoelectron microscopy of vitreous sections (Matias et al., 2003; Al-Amoudi et al., 2004; Zhang et al., 2004) show that the cytoplasmic membrane is clearly separated from the peptidoglycan (Fig. 3; Hoffmann et al., unpublished results). This distance and the periplasmic space between the inner and the outer membrane is exactly reflected by the ring structure of the flagellar basal body (Thomas et al., 2001) and the molecular size of the TolC-AcrB complex that bridges the periplasmic gap in E. coli (Murakami et al., 2002). Thus, under physiological conditions, the cell membrane is not pressed against the peptidoglycan layer and the pressure difference between cytoplasm and periplasm must be minimal. Membrane-derived charged oligosaccharides and other macromolecules are accumulated and trapped in the periplasm, account for a Donnan potential across the outer membrane (Stock et al., 1977; Miller et al., 1986; Sen et al., 1988), and serve as an osmotic buffer between the cytoplasm and the extracellular environment (Bartlett, 2000). This concept was challenged by Koch (1998), who concluded that the periplasm and the environment are almost in osmotic balance and that the cytoplasmic membrane must be pressed against the peptidoglycan under normal conditions. This assumption can now be refused by experimental evidence. Sudden hypoosmotic stress acts on the outer membrane first. Lipoproteins, OmpA-related outer membrane proteins (Baldermann et al., 1998) and periplasmic linker proteins (Engelhardt and Peters, 1998; Grizot and Buchanan, 2004) anchor the outer membrane to the peptidoglycan, which should prevent dilation in an analogous way to the S-layer-membrane assemblies in Archaea (Fig. 3; Engelhardt, 2007). It is highly conceivable that an S-layer sustains the outer membrane in addition (Section 2.1.2), particularly in the case of bacteria living in unprotected environments with fluctuating osmotic conditions.

Although it is less obvious, bacterial S-layers could also share a basic and common function similar to that in Archaea, albeit with reduced significance. There is reason to assume that $\mathrm{S}$ layers contribute to or determine the mechanical and osmotic stability of prokaryotic cells.

\section{Conclusion}

The survey on S-layer-cell envelope interactions, the discussion on shape maintenance, and on primary and secondary functions, all share the common aspect of cell or cell wall stabilisation. This fact has escaped attention essentially because the interactions of S-layers with other components in archaeal and bacterial cell envelopes and their significance for cell stability still await more detailed investigation. Studying S-layers in association with their interacting partners promises to increase our insight into Slayer functions (Engelhardt, 2007). But is there already enough information available to answer the initial question - are S-layers exoskeletons? The answer is split. Firstly, S-layers are not exoskeletons in a sense like the cuticula for arthropodes is, giving them a characteristic and apparently invariable shape. Shape-determining elements of microorganisms appear to be of endoskeletal origin. Secondly, S-layers are exoskeletons regarding their contribution to 
mechanical and osmotic cell stabilisation although, thirdly, this function is apparently not of equal importance in Archaea and Bacteria (and is still more hypothetical than proven for the latter). As a conclusion, S-layers possess characteristics of an exoskeleton but they are more like a mail shirt than a suit of armour.

\section{Acknowledgements}

The discussions with my always interested colleagues in the Department of Molecular Structural Biology were a stimulating help. I am grateful to all of them. Particular thanks are to Reinhard Guckenberger and Reiner Hegerl, and to Andrew Leis for critically reading the manuscript.

\section{References}

Al-Amoudi, A., Chang, J.-J., Leforestier, A., McDowall, A., Salamin, L.M., Norlén, L.P.O., Richter, K., Sartori-Blanc, N., Studer, D., Dubochet, J., 2004. Cryo-electron microscopy of vitreous sections. EMBO J. 23, 3583-3588.

Austin, J.W., Engel, A., Murray, R.G.E., Aebi, U., 1989. Structural analysis of the S-layer of Lampropedia hyalina. J. Ultrastruct. Mol. Struct. Res. 102, 255-264.

Baba, T., Toshima, Y., Minamikawa, H., Hato, M., Suzuki, K., Kamo, N., 1999. Formation and characterization of planar lipid bilayer membranes from synthetic phytanylchained glycolipids. Biochim. Biophys. Acta 1421, 91-102.

Baldermann, C., Lupas, A., Lubieniecki, J., Engelhardt, H., 1998. The regulated outer membrane protein Omp21 from Comamonas acidovorans is identified as a member of a new family of eight-stranded $\beta$-sheet proteins by its sequence and properties. J. Bacteriol. 180, 3741-3749.

Bartlett, D.H., 2000. Osmotic stress; in: Lederberg, J. (Ed.), Encyclopedia of Microbiology. San Diego, Academic Press, 2nd ed.,Vol. 3, pp. 502-516.

Baumeister, W., 2005. From proteomic inventory to architecture. FEBS Lett. 579, 933-937.

Baumeister, W., Wildhaber, I., Phipps, B.M., 1989. Principles of organization in eubacterial and archaebacterial surface proteins. Can. J. Microbiol. 35, 215-227.

Baumeister, W., Lembcke, G., 1992. Structural features of archaebacterial cell envelopes. J. Bioenerget. Biomembr. 24, 567-575.

Bayer, E.A., Shimon, L.J.W., Shoham, Y., Lamed, R., 1998. Cellulosomes - structure and ultrastructure. J. Struct. Biol. $124,221-234$

Beveridge, T.J., 2006. Understanding the shapes of bacteria just got more complicated. Mol. Microbiol. 62, 1-4.

Beveridge, T.J., Graham, L.L.,1991. Surface layers of bacteria. Microbiol. Rev. 55, 684-705.
Beveridge, T.J., Pouwels, P.H., Sára, M., Kotiranta, A., Lounatmaa, K., Karia, K., Kerosuo, E., Haapasalo, M., Egelseer, E.M., Schocher, I., Sleytr, U.B., Morelli, L., Callegari, M.-L., Nomellini, J.F., Bingle, W.H., Smit, J., Leibovitz, E., Lemaire, M., Miras, I., Salamitou, S., Béguin, P., Ohayon, H., Gounon, P., Matuschek, M., Sahm, K., Bahl, H., Grogono-Thomas, R., Dworkin, J., Blaser, M.J., Woodland, R.M., Newell, D.G., Kessel, M., Koval, S.F., 1997. Function of S-layers. FEMS Microbiol. Rev. 20, 99149.

Bingle, W.H., Engelhardt, H., Page, W.J., Baumeister, W., 1987. Three-dimensional structure of the regular tetragonal surface layer of Azotobacter vinelandii. J. Bacteriol. 169, 5008-5015.

Briegel, A., 2005. Anwendungsbeispiele für die KryoElektronentomographie an Prokaryonten. Dissertation, Tech. Univ. München.

Briegel, A., Dias, D.P., Li, Z., Jensen, R.B., Frangakis, A.S., Jensen, G.J., 2006. Multiple large filament bundles observed in Caulobacter crescentus by electron cryotomography. Mol. Microbiol. 62, 5-14.

Brock, T.D.,1981. Extreme thermophiles of the genera Thermus and Sulfolobus; in: Starr, M.P., Stolp, H., Trüper, H.G., Balows, A., Schlegel, H.G. (Eds.), The Prokaryotes. A Handbook on Habitats, Isolation, and Identification of Bacteria. Berlin, Springer-Verlag, Vol I, pp. 978-984.

Campo, N., Tjalsma, H., Buist, G., Stepniak, D., Meijer, M., Veenhus, M., Westermann, M., Müller, J.P., Bron, S., Kok, J., Kuipers, O.P., Jongloed, J.D.H., 2004. Subcellular sites for bacterial protein export. Mol. Microbiol. 53, 1583-1599.

Carballido-López, R., 2006. Orchestrating bacterial cell morphogenesis. Mol. Microbiol. 60, 815-819.

Chalcroft, J.P., Engelhardt, H., Baumeister, W., 1987. Structure of the porin from a bacterial stalk. FEMS Lett. $211,53-58$.

Chami, M., Bayan, N., Peyret, J.L., Kulik-Krzywicki, T., Lebon, G., Shechter, E., 1997. The S-layer protein of Corynebacterium glutamicum is anchored to the cell wall by its C-terminal hydrophobic domain. Mol. Microbiol. 23, 483-492.

Chauvaux, S., Matuschek, M., Beguin, P., 1999. Distinct affinity of binding sites for S-layer homologous domains in Clostridium thermocellum and Bacillus anthracis cell envelopes. J. Bacteriol. 181, 2455-2458.

Claus, H., Akça, E., Deaerdemaeker, T., Evrard, C., Declercq, J.-P., Harris, J.R, Schlott, B., König, H. 2005. Molecular organization of selected prokaryotic S-layer proteins. Can. J. Microbiol. 51, 731-743.

Couture-Tosi, E., Delacroix, H., Mignot, T., Mesnage, S., Chami, M., Fouet, A., Mosser, G., 2002. Structural analysis and evidence for dynamic emergence of Bacillus anthracis S-layer networks. J. Bacteriol. 184, 6448-6456. 
Daniel, R.A., Errington, J., 2003. Control of cell morphogenesis in bacteria: Two distinct ways to make a rod-shaped cell. Cell 113, 767-776.

Debabov, V.G., 2004. Bacterial and archaeal S-layers as subject of nanobiotechnology. Mol. Biol. 38, 578-591.

Desvaux, M., Dumas, E., Chafsey, I., Hébraud, M. 2006. Protein cell surface display in Gram-positive bacteria: from single protein to macromolecular protein structure. FEMS Microbiol. Lett. 256, 1-15.

Diederich, A., Sponer, C., Pum, D., Sleytr, U.B., Lösche, M., 1996. Reciprocal influence between the protein and lipid components of a lipid-protein membrane model. Coll. Surfaces B: Biointerfaces 6, 335-346.

Dooley, J.S.G., Engelhardt, H., Baumeister, W., Kay, W.W., Trust, T.J., 1989. Three-dimensional structure of an open form of the surface layer from the fish pathogen Aeromonas salmonicida. J. Bacteriol. 171, 190-197.

Dose, K., Rauchfuss, H., 1975. Chemische Evolution und der Ursprung lebender Systeme. Wissensch. Verlagsgesellschaft, Stuttgart.

Dworkin, J., Tummuru, M.K., Blaser, M.J., 1995. A lipopolysaccharide-binding domain of the Campylobacter fetus S-layer protein resides within the conserved $\mathrm{N}$ terminus of a familiy of silent and divergent homologs. J. Bacteriol. 177, 1734-1741.

Engelhardt, H., 1991. Electron microscopy of microbial cell wall proteins. Surface topography, three-dimensional reconstruction, and strategies for two-dimensional crystallization; in: Latgé, J.P., Boucias, D. (Eds.), Fungal Cell Wall and Immune Response. NATO ASI Series H53, Springer-Verlag, Berlin, pp. 11-25.

Engelhardt, H. 2007. Mechanism of osmoprotection by archaeal S-layers: A theoretical study. J. Struct. Biol. (online) DOI: 10.1016/j.jsb.2007.08.004

Engelhardt, H., Saxton, W.O., Baumeister, W., 1986. Threedimensional structure of the tetragonal surface layer of Sporosarcina ureae. J. Bacteriol. 168, 309-317.

Engelhardt, H., Gerbl-Rieger, S., Krezmar, D., SchneiderVoss, S., Engel, A., Baumeister, W., 1990. Structural properties of the outer membrane and the regular surface protein of Comamonas acidovorans. J. Struct. Biol. 105, 92102.

Engelhardt, H., Gerbl-Rieger, S., Santarius, U., Baumeister, W., 1991. The three-dimensional structure of the regular surface protein of Comamonas acidovorans derived from native outer membranes and reconstituted two-dimensional crystals. Mol. Microbiol. 5, 1695-1702.

Engelhardt, H., Peters, J., 1998. Structural research on surface layers - A focus on stability, surfacel layer homology domains, and surface layer-cell wall interactions. J. Struct. Biol. 124, 276-302.

Evrard, C., Declercq, J.-P., Debaerdemaeker, T., König, H.,1999. The first successful crystallization of a prokaryotic extremely thermophilif outer surface layer glycoprotein. Z. Kristallogr. 214, 427-429.

Firtel, M., Southam, G., Harauz, G., Beveridge, T.J.,1994. The organization of the paracrystalline multilayered spacerplugs of Methanospirillum hungatei. J. Struct. Biol. 112, 160-171.

Ford, M.J., Nomellini, J.F., Smit, J., 2007. S-layer anchoring and localization of an S-layer-associated protease in Caulobacter crescentus. J. Bacteriol. 189, 2226-2237.

Garduño, R.A., Phipps, B.M., Baumeister, W., Kay, W.W., 1992. Novel structural patterns in divalent cation-depleted surface layers of Aeromonas salmonicida. J. Struct. Biol. 109, 184-195.

Gerbl-Rieger, S., Engelhardt, H., Peters, J., Kehl, M., Lottspeich, F., Baumeister, W., 1992. Topology of the anion-selective porin Omp32 from Comamonas acidovorans. J. Struct. Biol. 108, 14-24.

Grizot, S., Buchanan, S.K., 2004. Structure of the OmpAlike domain of RmpM from Neisseria menigitidis. Mol. Microbiol. 51, 1027-1037.

Hansmeier, N., Bartels, F.W., Ros, R., Anselmetti, D., Tauch, A., Pühler, A., Kalinowski, J., 2004. Classification of hyper-variable Corynebacterium glutamicum surface-layer proteins by sequence analyses and atomic force microscopy. J. Biotechnol. 112, 177-193.

Harris, W.F., Scriven, L.E., 1970. Function of dislocations in cell walls and membranes. Nature 228, 827-829.

Hirn, R., Schuster, B., Sleytr, U.B., Bayerl, T.M.,1999. The effect of S-layer protein adsorption and crystallization on the collective motion of a planar lipid bilayer studied by dynamic light scattering. Biophys. J. 77, 2066-2074.

Howard, L.V., Dalton, D.D., McCoubrey jr. W., 1982. Expansion of the tetragonally arrayed cell wall protein layer during growth of Bacillus sphaericus. J. Bacteriol. 149, 748757.

Houwink, A.L., 1953. A macromolecular monolayer in the cell wall of Spirillum spec. Biochim. Biophys. Acta 10, 360366.

Houwink, A.L.,1956. Flagella, gas vacuoles and cell-wall structure in Halobacterium halobium; an electron microscope study. J. Gen. Microbiol. 15, 146-150.

Houwink, A.L., Le Poole, J.B., 1952. Eine Struktur in der Zellmembran einer Bakterie. Physikalische Verhandlungen 3,98 .

Huber, H., Hohn, M.J., Rachel, R., Fuchs, T., Wimmer, V.C., Stetter, K.O., 2002. A new phylum of Archaea: Represented by a nanosized hyperthermophilic symbiont. Nature 417, 63-67.

Ilk, N., Kosma, P., Puchberger, M., Egelseer, E.M., Mayer, H.F., Sleytr, U.B., Sára, M., 1999. Structural and functional analyses of the secondary cell wall polymer of Bacillus sphaericus CCM 2177 that serves as an S-layer-specific anchor. J. Bacteriol. 181, 7643-7646. 
Jensen, M.O., Mouritsen, O.G., 2004. Lipids do influence protein function - the hydrophobic matching hypothesis revisited. Biochim. Biophys. Acta 1666, 205-226.

Jing, H., Tagagi, J., Liu, J.-H., Lindgren, S., Zhang, R.-G., Joachimiak, A., Wang, J.-H., Springer, T.A., 2002. Archaeal surface layer proteins contain $\beta$ propeller, PKD, and $\beta$ helix domains and are related to metazoan cell surface proteins. Struct. 10, 1453-1464.

Karrasch, S., Hegerl, R., Hoh, J.H., Baumeister, W., Engel, A., 1994. Atomic force microscopy produces faithful highresolution images of protein surfaces in an aqueous environment. Proc. Natl. Acad. Sc.i USA 91, 836-838.

Kessel, M., Wildhaber, I., Cohen, S., Baumeister, W., 1988. Three-dimensional structure of the regular surface glycoprotein layer of Halobacterium volcanii from the Dead Sea. EMBO J. 7, 1549-1554.

Kessel, M., Volker, S., Santarius, U., Huber, R., Baumeister, W., 1990. Three-dimensional reconstruction of the surface protein of the extremely thermophilic archaebacterium Archaeoglobus fulgidus. System. Appl. Microbiol. 13, 207213

Koch, A.L., 1998. The biophysics of the Gram-negative periplasmic space. Crit. Rev. Microbiol. 24, 23-59.

Kocsis, E., Trus, B.L., Steven, A.C., Smith, P.R., Hannah, J.H., Brennan, M.J., Kessel, M., 1993. Orientation of porin channels in the outer membrane of Bordetella pertussis. Mol. Microbiol. 9, 469-476.

König, H., Rachel, R., Claus, H., 2007. Proteinaceous surface layers of Archaea: ultrastructure and biochemistry; in: Cavicchioli R (ed): Archaea - Molecular and Cellular Biology. American Soc. Microbiol. Press, Washington D.C., pp. 315-340.

Koga, Y., Morii, H., 2005. Recent advances in structural research on ether lipids from archaea including comparative and physiological aspects. Biosci. Biotechnol. Biochem. 69, 2019-2034.

Koval, S.F., Hynes, S.H., 1991. Effect of paracrystalline protein surface layers on predation by Bdellovibrio bacteriovorus. J. Bacteriol. 173, 2244-2249.

Küpcü, S., Lohner, K., Mader, C., Sleytr, U.B., 1998. Microcalorimetric study on the phase behaviour of S-layer coated liposomes. Mol. Membr. Biol. 15, 69-74.

Kürner, J., Frangakis, A.S., Baumeister, W., 2005. Cryoelectron tomography reveals the cytoskeletal structure of Spiroplasma melliferum. Science 307, 436-438.

Leaver, M., Errington, J., 2005. Roles for MreC and MreD proteins in helical growth of the cylindrical cell wall in Bacillus subtilis. Mol. Microbiol. 57, 1196-1209.

Lembcke, G., Baumeister, W., Beckmann, E., Zemlin, F., 1993. Cryo-electron microscopy of the surface protein of Sulfolobus shibatae. Ultramicroscopy 49, 397-406.
Löwe, J., van den Ent, F., Amos, L.A., 2004. Molecules of the bacterial cytoskeleton. Annu. Rev. Biophys. Biomol. Struct. 33, 177-198.

Lucic, V., Förster, F., Baumeister, W., 2005. Structural studies by electron tomography: from cells to molecules. Annu. Rev. Biochem. 74, 833-865.

Lupas, A., Engelhardt, H., Peters, J., Santarius, U., Volker, S., Baumeister, S., 1994. Domain structure of the Acetogenium kivui surface layer revealed by electron microscopy and sequence analysis. J. Bacteriol. 176, 1224-1233.

Mader, C., Küpcü, S., Sára, M., Sleytr, U.B., 1999. Stabilizing effect of an S-layer on liposomes towards thermal and mechanical stress. Biochim. Biophys. Acta $1418,106-116$.

Matias, V.R.F., Al-Amoudi, A., Dubochet, J., Beveridge, T.J., 2003. Cryo-transmission electron microscopy of frazen-hydrated sections of Escherichia coli and Pseudomonas aeruginosa. J. Bacteriol. 185, 6112-6118.

Matias, V.R.F., Beveridge, T.J., 2005. Cry-electron microscopy reveals native polymeric cell wall structure in Bacillus subtilis 168 and the existence of a periplasmic space. Mol. Microbiol. 56, 240-251.

Matias, V.R.G., Beveridge, T.J., 2006. Native cell wall organization shown by cryo-electron microscopy confirms the existence of a periplasmic space in Staphylococcus aureus. J .Bacteriol. 188, 1011-1021.

May, A., Pusztahelyi, T., Hoffmann, H., Fischer, H.-J., Bahl, H., 2006. Mutagenesis of conserved charged amino acids in SLH domains of Thermoanaerobacterium thermosulfurigenes EM1 affects attachment to cell wall sacculi. Arch Microbiol 185, 263-269.

Mertig, M., Kirsch, R., Pompe, W., Engelhardt, H.,1999. Fabrication of highly oriented nanocluster arrays by biomolecular templating. Eur. Phys. J. D 9, 45-48.

Mescher, M.F., Strominger, J.L.,1976. Structural (shapemaintaining) role of the cell surface glycoprotein of Halobacterium salinarium. Proc. Natl. Acad. Sci. USA 73, 2687-2691.

Mesnage, S., Fontaine, T., Mignot, T., Delepierre, M., Mock, M., Fouet, A., 2000. Bacterial SLH domain proteins are non-covalently anchored to the celle surface via a conserved mechanism involving wall polysaccharide pyruvylation. EMBO J. 19, 4473-4484.

Messner, P., Pum, D., Sára, M., Stetter, K.O., Sleytr, U.B., 1986a. Ultrastructure of the cell envelope of the archaebacteria Thermoproteus tenax and Thermoproteus neutrophilus. J. Bacteriol. 166, 1046-1054.

Messner, P., Pum, D., Sleytr, U.B., 1986b. Characterization of the ultrastructure and the self-assembly of the surface layer of Bacillus stearothermophilus strain NRS 2004/3a. J. Ultrastruct. Mol. Res. 97, 73-88. 
Miller, K.J., Kennedy, E.P., Reinhold, V.N., 1986. Osmotic adapataion by gram-negative bacteria: possible role for periplasmic oligosaccharides. Science 231, 48-51.

Müller, D.J., Baumeister, W., Engel, A., 1996. Conformational change of the hexagonally packed intermediate layer of Deincoccus radiodurans monitored by atomic force microscopy. J. Bacteriol. 178, 3025-3030.

Murakami, S., Nakashima, R., Yamashita, E., Yamaguchi, A., 2002. Crystal structure of bacterial multidrug efflux transporter AcrB. Nature 419, 587-593.

Murray, R.G.E., 1988. A structured life. Ann. Rev. Microbiol. 42, 1-34.

Nomellini, J.F., Kupcu, S., Sleytr, U.B., Smit, J., 1997. Factors controlling in vitro recrystallization of the Caulobacter crescentus paracrystalline S-layer. J. Bacteriol. $179,6349-6354$.

Paul, A., Engelhardt, H., Jakubowski, U., Baumeister, W., 1992. Two-dimensional crystallization of a bacterial surface protein on lipid vesicles under controlled conditions. Biophys. J. 61, 172-188.

Peters, J., Peters, M., Lottspeich, F., Schäfer, W., Baumeister, W., 1987. Nucleotide sequence analysis of the gene encoding the Deinococcus radiodurans surface protein, derived amino acid sequence, and complementary protein chemical studies. J. Bacteriol. 169, 5216-5223.

Phipps, B.M., Engelhardt, H., Huber, R., Baumeister, W., 1990. Three-dimensional structure of the crystalline protein envelope layer of the hyperthermophilic archaebacterium Pyrobaculum islandicum. J. Struct. Biol. 103, 152-163.

Phipps, B.M., Huber, R., Baumeister, W., 1991. The cell envelope of the hyperthermophilic archaebacterium Pyrobaculum organotrophum consists of two regularly arrayed protein layers: three-dimensional structure of the outer layer. Mol. Microbiol. 5, 253-265.

Prüschenk, R., Baumeister, W., Zillig, W.,1987. Surface structure variants in different species of Sulfolobus. FEMS Microbiol. Lett. 43, 327-330.

Pum, D., Messner, P., Sleytr, U.B., 1991. Role of the S layer in morphogenesis and cell division of the archaebacterium Methanocorpusculum sinense. J. Bacteriol. 173, 6865-6873.

Roeben, A., Kofler, C., Nagy, I., Nickell, S., Hartl, F.U., Bracher, A., 2007. Crystal structure of an archaeal actin homolog. J. Mol. Biol. 358, 145-156.

Sára, M., Moser-Thier, K., Kainz, U., Sleytr, U.B., 1990. Characterization of S-layers from mesophilic bacillaceae and studies on their protective role towards muramidases. Arch. Microbiol. 153, 209-214.

Sára, M., Egelseer, E.M., 1996. Functional aspects of Slayers; in: Sleytr, U.B., Messner, P., Pum, D., Sára, M. (Eds.), Crystalline Bacterial Cell Surface Proteins. Landes Comp., Austin, pp. 103-131.
Sára, M., Sleytr, U.B., 2000. S-layer proteins. J. Bacteriol. $182,859-868$

Sára, M., Pum, D., Huber, C., Ilk, N., Pleschberger, M., Sleytr, U.B., 2006. Nanoscale patterning of S-layer proteins as a natural self-assembly system; in: Kumar, C.S.S.R. (Ed.), Nanotechnologies for the Life Sciences. Biological and Pharamceutical Nanomaterials. Wiley-Verlag, Weinheim, Vol.2, pp. 219-252.

Schäffer, C., Messner, P., 2005. The structure of secondary cell wall polymers: how Gram-positive bacteria stick their cell walls together. Microbiol. 151, 643-651.

Schuster, B., Pum, D., Sleytr, U.B., 1998. Voltage clamp studies on S-layer-supported tetrether lipid membranes. Biochim. Biophys. Acta 1369, 51-60.

Schuster, B., Sleytr, U.B., Diederich, A., Bähr, G., Winterhalter, M., 1999. Probing the stability of S-layersupported planar lipid membranes. Eur. Biophys. J. 28, 583590.

Schuster, B., Sleytr, U.B., 2002. The effect of hydrostatic pressure on S-layer-supported lipid membranes. Biochim. Biophys. Acta 1563, 29-34.

Sen, K., Hellman, J., Nikaido, H., 1988. Porin channels in intact cells of Escherichia coli are not affected by Donnan potentials across the outer membrane. J. Biol. Chem. 263, $1182-11870$

Shiomi, D., Yoshimoto, M., Homma, M., Kawagishi, I., 2006. Helical distribution of the bacterial chemoreceptor via colocalization with the Sec protein translocation machinery. Mol. Microbiol. 60, 894-906.

Sleytr, U.B., Plohberger, R., 1980. The dynamic process of assembly of two-dimensional arrays of macromolecules; in: Baumeister. W, Vogell, W. (Eds.): Electron Microscopy at Molecular Dimensions. Springer, Berlin, pp. 36-47.

Sleytr, U.B., Messner, P., Pum, D., Sára, M., 1999. Crystalline bacterial cell surface layers (S layers): From supramolecular cell structure to biomimetics and nanotechnology. Angew. Chem. Int. Ed. 38, 1034-1054.

Sleytr, U.B., Sára, M., Pum, D., Schuster, B., 2001. Characterization and use of crystalline bacterial cell surface layers. Progr. Surf. Sci. 68, 231-278.

Smith, S.H., Murray, R.G.E., 1990. The structure and associations of the double $\mathrm{S}$ layer on the cell wall of Aquaspirillum sinuosum. Can. J. Microbiol. 36, 327-335.

Smit, E., Oling, F., Demel, R., Martinez, B., Pouwels, P.H., 2001. The S-layer protein of Lactobacillus acidophilus ATCC 4356: identification and characterization of domains responsible for S-protein assembly and cell wall binding. J. Mol. Biol. 305, 245-257.

Smit, E., Pouwels, P.H., 2002. One repeat of the cell wall binding domain is sufficient for anchoring the Lactobacillus acidophilus surface layer protein. J. Bacteriol. 184, 4174619. 
Stetefeld, J., Jenny, M., Schulthess, T., Landwehr, R., Engel, J., Kammerer, R.A., 2000. Crystal structure of a naturally occuring parallel right-handed coiled coil tetramer. Nat. Struct. Biol. 7, 772-776.

Stetter, K.O., 1986. Diversity of extremely thermophilic archaebacteria; in: Brock, T.D. (Ed.), Thermophiles. General, Molecular, and Applied Microbiology. John Wiley $\&$ Sons, New York, pp. 39-74.

Stewart, G.C., 2005. Taking shape: control of bacterial cell wall biosynthesis. Mol. Microbiol. 57, 1177-1181.

Stock, J.B., Rauch, B., Roseman, S., 1977. Periplasmic space in Salmonella typhimurium and Escherichia coli. J. Biol. Chem. 252, 7850-7861.

Thomas, D., Morgan, D.G., DeRosier, D.J., 2001. Structures of bacterial flagellar motors from two FliF-FliG gene fusion mutants. J. Bacteriol. 183, 6404-6412.

Trachtenberg, S., Pinnick, B., Kessel, M., 2000. The cell surface glycoprotein layer of the extreme halophile Halobacterium salinarum and its relation to haloferax volcanii: Cryo-electron tomography of freeze-substituted cells and projection studies of negatively stained envelopes. J. Struct. Biol. 130, 10-26.

Tsuboi, A., Engelhardt, H., Santarius, U., Tsukagoshi, N., Udaka, S., Baumeister, W.,1989. Three-dimensional structure of the surface protein layer (MW layer) of Bacillus brevis 47. J. Ultrastruct. Mol. Struct. Res. 102, 178-187.

Walker S.G., Karunaratne, D.N., Ravenscroft, N., Smit, J., 1994. Characterization of mutants of Caulobacter crescentus defective in surface attachment of the paracystalline surface layer. J. Bacteriol. 176, 6321-6323.

Wang, L., Slayden, R.A., Barry III, C.E., Liu, J., 2000. Cell wall structure of a mutant of Mycbacterium smegmatis defective in the biosynthesis of mycolic acids. J. Biol. Chem. 275, 7224-7229.

Weygand, M., Kjaer, K., Howes, P.B., Wetzer, B., Pum, D., Sleytr, U.B., Lösche, M., 2002. Structural reorganization of phospholipid headgroups upon recrystallization of an Slayer lattice. J. Phys. Chem. B 106, 5793-5799.

Wildhaber, I., Baumeister, W., 1987. The cell envelope of Thermoproteus tenax: three-dimensional structure of the surface layer and its role in shape maintenance. EMBO J. 6, $1475-1480$.

Wildhaber, I., Santarius, U., Baumeister, W., 1987. Threedimensional structure of the surface protein of Desulfurococcus mobilis. J. Bacteriol. 169, 5563-5568.

Zhang, P., Bos, E., Heymann, J., Gnaegi, H., Kessel, M., Peters, P.J., Subramaniam, S., 2004. Direct visualization of receptor arrays in frozen-hydrated sections and plungefrozen specimens of E. coli engineered to overproduce the chemotaxis receptor Tsr. J. Microscopy 216, 76-83.

Zhao, G., Ali, E., Sakka, M., Kimura, T., Sakka, K., 2006. Binding of S-layer homology modules from Clostridium thermocellum SdbA to peptidoglycans. App. Microbiol. Biotechnol. 70, 464-469.

Zillig, W., Stetter, K.O., Schäfer, W., Janekovic, D., Wunderl, S., Holz, I., Palm, P., 1981. Thermoproteales: A novel type of extremely thermoacidophilic anaerobic archaebacteria isolated from Icelandic solfataras. Zbl. Bakt. Hyg. I. Abt. Orig. C 2, 205-227. 